Abstract 606 Table 1

\begin{tabular}{|c|c|c|c|c|c|c|}
\hline & \multicolumn{2}{|c|}{ Dose $(\mathrm{mg} / \mathrm{kg})$} & \multicolumn{2}{|c|}{ Frequency (Hours) } & \multicolumn{2}{|c|}{ Total daily dose (mg/kg/24h) } \\
\hline & Median & Min - Max & Median & Min - Max & Median & Min - Max \\
\hline Furosemide & 1 & $0.5-3$ & 12 & $6-24$ & 2 & $1-4$ \\
\hline Spironolactone & 1 & $0.5-10$ & 12 & $12-24$ & 2 & $1-20$ \\
\hline Chlorthiazide & 10 & $1-25$ & 12 & $12-24$ & 20 & $2-50$ \\
\hline Hydrochlorthiazide & 15 & $10-20$ & 12 & 12 & 30 & $20-40$ \\
\hline
\end{tabular}

1J Chahal, ${ }^{2} \mathrm{D}$ Jennings, 'M Turner. 'Neonatal Unit, Liverpool Women's NHS Foundation Trust, Liverpool; ${ }^{2}$ National Perinatal Epidemiology Unit (NPEU), University of Oxford, Oxford, UK

Background Diuretics are used in premature babies with chronic lung disease despite minimal evidence. The aim of this study was to assess the use of diuretics in neonatal units in England.

Method An electronic survey using Survey Monkey was sent to 108 units in the Medicines for Children Research Network Neonatal Network.

Results There were 66 responses with useable data from 55 unique units. $20 \%$ had a protocol for use. $49 \%$ would consider starting diuretics after 5 weeks of age and half would start diuretics in situations such as being unable to wean ventilation, unable to extubate, unable to wean off CPAP, chronic lung disease and chronic lung disease in the presence of a PDA. $70 \%$ had no rule when to stop diuretics, $22 \%$ stopped off supplemental oxygen and $8 \%$ off CPAP.

$48 \%$ use chlorthiazide plus spironolactone in babies who are fully fed and $84 \%$ prefer furosemide in babies requiring intravenous treatment.

Table 1 shows the variation in the doses within diuretics.

Conclusions There is wide heterogeneity in the use of diuretics in England. The majority use chlorthiazide plus spironolactone in babies who are fed and furosemide intravenously.

\section{RISK FACTORS FOR INTRAVENTRICULAR HEMORRHAGE IN LESS THAN 32 WEEKS GESTATION PRETERM INFANTS - PROSPECTIVE STUDY}

doi:10.1136/archdischild-2012-302724.0607

1,2ML Ognean, ${ }^{3} \mathrm{E}$ Olariu, ${ }^{3} \mathrm{O}$ Boanta, ${ }^{3} \mathrm{~A}$ Nicula, ${ }^{4} \mathrm{G}$ Gradinariu, ${ }^{3} \mathrm{M}$ Mutiu. ${ }^{1}$ Neonatology, Clinical County Hospital Sibiu; ${ }^{2}$ Faculty of Medicine - Sibiu, ${ }^{3}$ Clinical County Hospital Sibiu; ${ }^{4}$ Clinical Hospital of Pediatrics, Sibiu, Romania

Chronic lung disease (CLD) of prematurity may complicate the postnatal development of the severe respiratory distress syndrome (RDS) and negatively affect the long term neurodevelopmental outcome of the premature infant.

Aim To evaluate the risk factors for CLD in $\leq 32$ weeks gestation preterm infants.

Methods The study was developed in the Neonatology Dpt. of the Clinical County Emergency Hospital Sibiu between 01.01.201031.12.2011. The study group comprised 139 preterm infants with a mean GA of $30.26 \pm 1.93$ weeks (24-32 weeks) and a mean BW of $1412.99 \pm 367.389 \mathrm{~g}(600-2270 \mathrm{~g})$. The prospectively collected data were analysed using IBM SPSS 19.0 and were considered significant at a $p<0.05$.

Results CLD occurred with an incidence of $7.91 \%$ in the study group. The preterm infants that developed CLD had significantly lower GA ( $p$ 0.000), BW ( $p$ 0.000), and Apgar score at 1 minute ( $p$ 0.014). Significantly longer duration of the oxygen therapy (0.000), CPAP support (0.000), mechanical ventilation ( $p 0.003$ ) and hospitalization ( $p$ 0.003) were found in those preterm infants that developed CLD compared with those without CLD. A significant association was found between CLD and apnea of prematurity, neonatal sepsis, nosocomial infection and ROP even after excluding deaths and outborn infants.

Conclusions Low GA, BW, the severity of RDS but also the presence of perinatal infection were the main risk factors identified in preterm infants with CLD.

\section{REDUCED LIPOXIN A 4 /LEUKOTRIENE B ${ }_{4}$ RATIO IN EARLY CF BAL - IMPAIRED AIRWAY EPITHELIAL LIPOXIN $A_{4}$ SYNTHESIS CAPACITY}

doi:10.1136/archdischild-2012-302724.0608

${ }^{1} \mathrm{~F}$ Ringholz, ${ }^{2 P}$ McNally, 'V Urbach, SHIELD CF. 'National Children's Research Centre, ${ }^{2}$ Respiratory Department, Our Lady's Children's Hospital Crumlin Dublin 12, Dublin, Ireland

Cystic Fibrosis (CF) is characterised by impaired muco-ciliary clearance, persistent neutrophilic inflammation and bacterial infection. Normal resolution of inflammation involves an active switch in mediators that predominate in exudates. Early in inflammation, Leukotriene $\mathrm{B}_{4}\left(\mathrm{LTB}_{4}\right)$ plays a role in neutrophil activation. Resolution and return to tissue homeostasis are signalled by the transcellular synthesis of Lipoxin $\mathrm{A}_{4}\left(\mathrm{LXA}_{4}\right)$ by the action of Lipoxygenase enzymes (LO) expressed in cells such as neutrophils and airway epithelial cells.

The aims of this study were to quantify LXA production in the airways of children with CF and characterise $\mathrm{LXA}_{4}$ synthesis by airway epithelial cells in CF.

$\mathrm{LXA}_{4}$ and $\mathrm{LTB}_{4}$ were measured in paediatric BAL samples by ELISA. We quantified the capacity of Non CF (NuLi-1) and CF (CuFi-1 Homozygous $\Delta$ F508) cells cultured as differentiated bronchial epithelia to synthesize $\mathrm{LXA}_{4}$ by the action of $15-\mathrm{LO}$ on 5(S),6(R)-DiHETE, (a precursor of $\mathrm{LXA}_{4}$ ). Expression of 15-LO was measured by Western Blot.

Relative production of $\mathrm{LXA}_{4}$ is significantly depressed in paediatric CF patients versus controls when compared to $\mathrm{LTB}_{4}$. The ability of CuFi-1 cells to convert 5(S), 6(R)-DiHETE to LXA 4 was reduced as compared with NuLi-1 cells. The expression of 15-LO2 was reduced in CuFi-1 compared with Nuli-1 cells.

The ratio of $\mathrm{LXA}_{4}$ to $\mathrm{LTB}_{4}$ in the airway of young children with $\mathrm{CF}$ is depressed. Our results indicate that the contribution of airway epithelial cells to Lipoxin $\mathrm{A}_{4}$ synthesis is reduced in CF. This may contribute to the persistence of acute inflammation and consequent lung damage in CF.

\begin{tabular}{ll}
\hline 609 & SPECIFITY OF TUBERCULOSIS AND RESISTENCE OF \\
THERAPY BETWEEN IMMIGRANTS AND BOSNIA-BORN \\
CHILDREN
\end{tabular}

doi:10.1136/archdischild-2012-302724.0609

'A Bajraktarevic, 'S Maglajilia, 'A Mahinic, 'M Miokovic, 'A Pahor Kurilic, 'L Kumasin, ${ }^{2} \mathrm{~L}$ Sporisevic, ${ }^{1} \mathrm{~A}$ Selimovic, ${ }^{3} \mathrm{Z}$ Jatic, ${ }^{4} \mathrm{Z}$ Guzin, ${ }^{5} \mathrm{~T}$ Frankic, ${ }^{6} \mathrm{~B}$ Pojskic Arnautovic, ${ }^{7}$ A Latifagic, ${ }^{8} \mathrm{E}$ Mujicic Selimovic, ${ }^{8} \mathrm{G}$ Sulejmanpasic. ${ }^{1}$ Pediatrics Department, Public Health Institution of Sarajevo Canton; ${ }^{2}$ Pediatrics Department, First Medical Aid; 
${ }^{3}$ Department for Family Medicine, Medical Faculty Sarajevo, Sarajevo; ${ }^{4}$ Pediatrics Surgery, Clinical Center Mostar, Mostar; ${ }^{5}$ Department for Pharmacology, Pharmaceutical Faculty Sarajevo, Sarajevo; ${ }^{6}$ Cardiology Department, Cantonal Hospital Zenica, Zenica; ${ }^{7}$ Pediatrics Department, Pediatrics Clinic, Tuzla; ${ }^{8}$ Pediatrics Department, Clinical Medical Center, Sarajevo, Bosnia-Herzegovina

Introduction Migration refers to the movement of persons or children from an origin place to a destination place across some predefined, political boundary. Since the 1995s after war, Bosnia and Herzegovina has continued being a country of mass children immigration from Sandjak, Kosovo, Serbia, Monte Negro and sporadic immigration from China.

Methods The presence of tuberculosis disease in the Immigrants children or foreign-born child should prompt the pediatricians to collect appropriate specimens to recover an organism. We conducted a secondary data analysis focusing on immigrants children sampled in the 1995 through 2010 versions of the National Bosnian Children Health Records Survey.

Results The increase in tuberculosis among Gypsy children in Sarajevo coincided with similar increases in immigration into Bosnia and Herzegovina. Medical records were available for review to assess adequately potential missed opportunities to prevent tuberculosis in children from Sandjak in only $1.5 \%$ of cases and Gypsies in 33\% cases. Most children with drug-resistant tuberculosis were Gypsy (18.1\%) or Chinese Asian (11.2\%), and $16.4 \%$ of children or their parents were from a Bosnia and Herzegovina regions in which tuberculosis is highly endemic as Sarajevo Canton mountain area.

Conclusions Pediatricians should be aware of the special health problems as tuberculosis for which immigrant children are at risk. Immigration poses unique stresses on children and families. There were no significance difference between incidence of tuberculosis and resistence on therapy between children from Sandjak and Bosnia but that differences were higher in case of Gypsies children.

\section{TOTAL PARENTERAL NUTRITION AS A SOURCE OF OXIDANT LOAD LEADING TO BRONCHOPULMOANRY DYPLASIA}

doi:10.1136/archdischild-2012-302724.0610

${ }^{1}$ ISI Mohamed, ${ }^{2 T}$ Rouleux, ${ }^{2,3} \mathrm{JC}$ Lavoie. ${ }^{1}$ Pediatrics, Division of Neonatology, University of Montreal, Sainte-Justine Hospital; ${ }^{2}$ Centre de Recherche; ${ }^{3}$ Pediatrics- Neonatology, Universite de Montreal - CHU Sainte-Justine, Montréal, OC, Canada

Background Immaturity of antioxidant defense coupled with oxidant load is suspected to induce the development of bronchopulmonary dyplasia (BPD) in premature infants. Peroxide load from total parenteral nutrition (TPN) is associated with oxidative stress in this population. We hypothesize that the oxidative stress and, consequently, the severity of $\mathrm{BPD}$, both increase in function of duration of TPN infusion.

Objective To document the relation between the duration of TPN as well as the redox potential of glutathione measured in blood and the severity of BPD.

Design/methods GSH and GSSG from whole blood sampled at 36 weeks of corrected age in 51 infants less than 29 weeks of gestational age, were measured by capillary electrophoresis in order to calculate the redox potential (Nernst equation). Severity of BPD was classified according to NICH guidelines (Job and Bancalari, 2001). Means (s.e.m). ( $n=5-21$ per group) were compared by ANOVA.

Results The duration of TPN in days was strongly associated $(p<0.001)$ with the severity of BPD. A logestic regression model confirmed the independent effect of TPN.

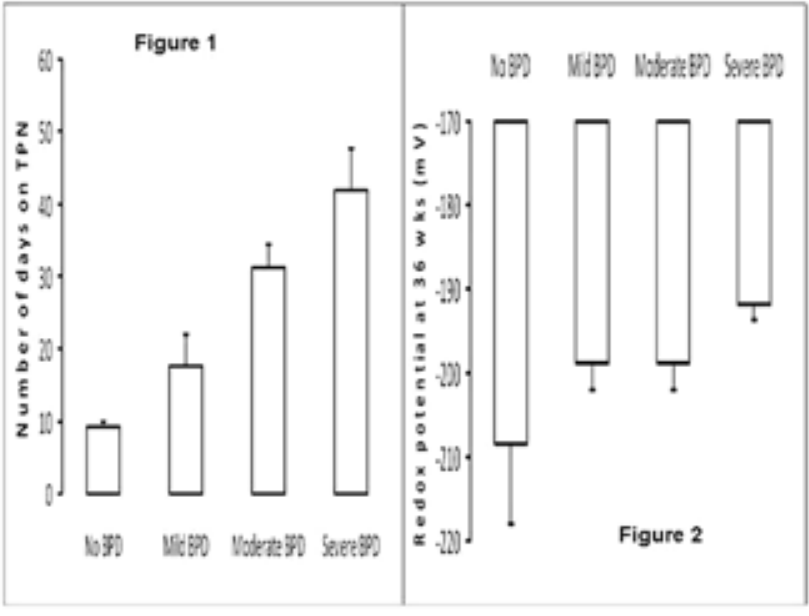

Abstract 610 Figure 1 TPN, redox potential and BPD

Conclusions The duration of the oxidant load from TPN exacerbates the oxidative stress in preterm infants as observed with the more oxidized status of the redox potential in infants having received TPN for a longer time. The strong relation between severity of BPD and duration of TPN could be explained by this oxidative stress generated by the TPN

\section{OESOPHAGEAL ATRESIA AND ASSOCIATED ANOMALIES}

doi:10.1136/archdischild-2012-302724.0611

P Desai, J Morris, L Segal. St George's Hospital NHS Trust, London, UK

Background In previous studies the incidence of associated congenital anomalies for infants with oesophageal atresia(OA) ranges between $40-57 \%$. OA mostly associated with Tracheoesophageal fistula is a part of VACTERL association (Vertebral anomalies, Anal atresia, Cardiovascular anomalies, Tracheoesophageal fistula, Renal/ or radial anomalies, Limb defects).

Aim To determine the incidence of associated anomalies in babies with oesophageal atresia.

Methods 32 babies treated for oesophageal atresia at our regional surgical neonatal unit between the period February 2007 to February 2012 were included in the study.

Results Out of 32 babies, 17 were male and 15 were female infants with gestation ranging from 31-40 weeks. 10 babies (31\%) were born in-utero and 22 babies were transferred from local neonatal units. Birth weights ranged between $1380 \mathrm{~g}-4300 \mathrm{~g}$.

In total 15 babies (47\%) had some form of Cardiac anomalies with 5 babies either having Atrial septal defect or Ventricular septal defect and 8 babies having a patent ductus arteriosus (PDA).

3 babies ( $9 \%$ ) had associated anorectal anomalies.

In total 10 babies (31\%) had associated anomaly excluding isolated PDA and 16 babies (50\%) if isolated PDA were included.

Conlcusion Association of anomalies with Oesophageal anomalies is well documented in literature. It is important to identify vertebral anomalies early for follow up as the risk of scoliosis is 13 fold after repair of $O A$ in relation to general population. This small study showed incidence of $50 \%$ for babies with $\mathrm{OA}$ to be associated with other anomalies and supports current literature.

\section{FEASBILITY STUDY USING FACIAL ANALYSIS SOFTWARE TO DOCUMENT FACIAL FEATURES ASSOCIATED WITH FETAL ALCOHOL SYNDROME IN NEWBORN INFANTS}

doi:10.1136/archdischild-2012-302724.0612 